\title{
The role of the Src Homology-2 domain containing protein B (SHB) in $\beta$ cells
}

\author{
Michael Welsh, Maria Jamalpour, Guangxiang Zang ${ }^{\dagger}$ and Björn Åkerblom
}

Department of Medical Cell Biology, Uppsala University, PO Box 571, Husargatan 3, SE-75123 Uppsala, Sweden

${ }^{\dagger} \mathrm{G}$ Zang is now at Department of Medical Biosciences, Umeå University, Umeå, Sweden

Correspondence should be addressed to M Welsh

Email

Michael.welsh@mcb.uu.se

\begin{abstract}
This review will describe the $\mathrm{SH}$-domain signaling protein Src Homology-2 domain containing protein $\mathrm{B}(\mathrm{SHB})$ and its role in various physiological processes relating in particular to glucose homeostasis and $\beta$ cell function. SHB operates downstream of several tyrosine kinase receptors and assembles signaling complexes in response to receptor activation by interacting with other signaling proteins via its other domains (proline-rich, phosphotyrosine-binding and tyrosine-phosphorylation sites). The subsequent responses are context-dependent. Absence of $S h b$ in mice has been found to exert effects on hematopoiesis, angiogenesis and glucose metabolism. Specifically, first-phase insulin secretion in response to glucose was impaired and this effect was related to altered characteristics of focal adhesion kinase activation modulating signaling through Akt, ERK, $\beta$ catenin and CAMP. It is believed that SHB plays a role in integrating adaptive responses to various stimuli by simultaneously modulating cellular responses in different cell-types, thus

playing a role in maintaining physiological homeostasis.
\end{abstract}

Key Words

- signal transduction

\section{Introduction}

The limited replicative capacity of human pancreatic $\beta$ cells contributes significantly to the development of diabetes mellitus and thus comprises a major hurdle for possible treatment and/or prevention of this disease. In early attempts to understand $\beta$ cell function and particularly $\beta$ cell replication, cDNA library subtraction-screening procedures were performed to identify genes that were selectively expressed in proliferating $\beta$ cells. Positive hits were considered as genes relating to $\beta$ cell proliferation and expansion of the $\beta$ cell mass. One candidate gene identified by such procedures was the Reg1 (REG1A) gene that was induced in $\beta$ cells regenerating after partial pancreatectomy (Terazono et al. 1990). In a similar attempt to identify genes induced in replicating $\beta$ cells
( $\beta$ TC1 cells) after serum-stimulation, the Src Homology-2 domain containing adapter protein B (SHB) was identified (Welsh et al. 1994). This review will describe the subsequent progress in our understanding of the role of this protein in various processes, with particular focus on $\beta$ cell function.

\section{The SHB adapter protein}

The SHB gene is located on chromosome 9 (nt 3806921337915898 in coding direction, http://www.ncbi.nlm. nih.gov/gene/6461 for the human $S H B$ gene) and ubiquitously expressed (see http://www.ebi.ac.uk/gxa/genes/ ENSG00000107338 and http://www.gtexportal.org/

Published by Bioscientifica Ltd 
home/gene/SHB for recent RNAseq data and http://biogps. org $/$ \#goto=genereport\&id=6461 for microarray data on $S H B$ gene expression in various human tissues). The human SHB protein has a mass of approximately $55 \mathrm{kDa}$ (509 amino acids) and consists of several identified domains; N-terminal proline-rich motifs followed by a phosphotyrosine-binding (PTB) domain, tyrosine phosphorylation sites and a C-terminal SH2 domain (Anneren et al. 2003). Interspecies SHB sequence identity is very high in the C-terminus (Fig. 1), whereas it is much lower in the $\mathrm{N}$-terminal half except for certain segments, including one of the proline-rich motifs (boxed sequences) and parts of the sequences that potentially comprise the PTB domain. The PTB domain has not been mapped in detail but is contained within a region starting at amino acid 77 and ending at amino acid 389 (human SHB sequence, blue line with arrow over the sequences in figure) and preferentially recognizes the sequence $\mathrm{D}-\mathrm{D}-\mathrm{X}-\mathrm{pY}$ on interacting partners
(Welsh et al. 1998). Several tyrosine phosphorylation sites have been described (http://www.phosphosite.org/proteinAction.do? $\mathrm{id}=5046 \&$ showAllSites $=$ true), of which five have been indicated (boxed). The four C-terminal tyrosine phosphorylation sites exhibit a high degree of identity between each other, showing a tyrosine (Y) followed by two $\mathrm{X}-\mathrm{X}$ (of which one is D or E)-P-Y/P/W (aromatic)-D/E. In the C-terminus, there is an $\mathrm{SH} 2$ domain preferentially recognizing the target sequence pY-T/I/V-X-L that can also be written in a more general form as pY-hydrophobic-Xhydrophobic-D/E-hydrophobic (Welsh et al. 1994, Anneren et al. 2003, Liu et al. 2012). The domains have different interacting partners and the role of SHB is to generate signaling complexes upon activation. These complexes are context-dependent, i.e., dependent on cell type and conditions the cells are exposed to (growth factors, degree of activation, exposure to stress, etc) and consequently have unique effects on the cells in various settings.
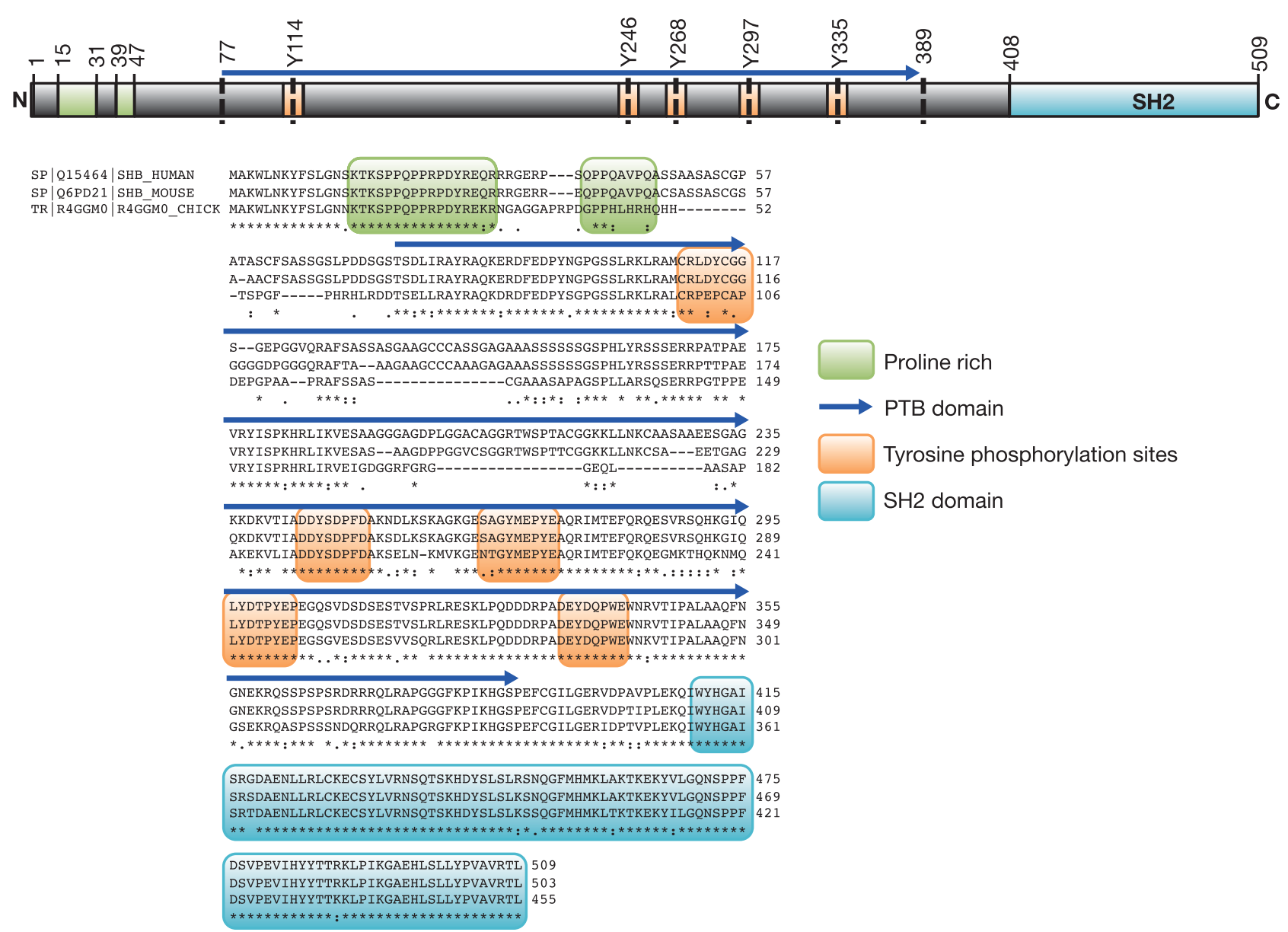

Figure 1

SHB schematic structure and amino acid sequence comparison between human, mouse and chick SHB. Proline-rich motifs, tyrosine-phosphorylation sites, $\mathrm{SH} 2$ domain and sequence used to define the PTB domain have been indicated.

http://jme.endocrinology-journals.org DOI: 10.1530/JME-15-0228
(C) 2016 Society for Endocrinology Printed in Great Britain
Published by Bioscientifica Ltd 
The proline-rich sequences in the $\mathrm{N}$-terminus have been shown to interact with signaling proteins such as Src-family kinases, phospholipase C-gamma (PLC- $\gamma$ ), the p85 subunit of phosphatidyl-inositide $3^{\prime}$ kinase (PI3K), epidermal growth factor receptor pathway substrate 8 (EPS8), Janus kinase (JAK)-1/3 and c-Abl (Anneren et al. 2003, Hagerkvist et al. 2007a). The PTB domain interacts with focal adhesion kinase (FAK), Vav1 and linker for activation T cells (LAT) (Anneren et al. 2003). The phosphorylation sites interact with CrkII, SH2-domain-containing leukocyte protein of 76 (SLP76), Ras-GTPase activating protein (RasGAP) and c-Abl (Anneren et al. 2003, Hagerkvist et al. 2007a). Studies using the individually mutated phosphorylation sites failed to reveal any site-specific interaction (Hagerkvist et al. 2007a) and this is a likely consequence of the high degree of sequence identity among four of the phosphorylation sites. Finally, the SH2 domain has been shown to interact with the platelet-derived growth factor receptors (PDGFRA and PDGFRB), fibroblast growth factor receptor-1 (FGFR1), vascular endothelial growth factor receptor-2 (VEGFR2), T cell receptor (TCR), interleukin-2R, EphB2 (ephrin receptor) and c-Met (Lindholm 2002, Anneren et al. 2003, Holmqvist et al. 2004, Jorgensen et al. 2009, Leung et al. 2014). SHB becomes tyrosine-phosphorylated upon stimulation of the PDGF receptors, FGFR1, T cell receptor, VEGFR2, c-Src-family kinases, EphB2 and the angiogenesis inhibitor endostatin. SHB also binds the growth hormone receptor (Moutoussamy et al. 1998) and the Epstein-Barr virus protein LMP2A (Matskova et al. 2007), of which the latter causes SHB tyrosine phosphorylation by Syk and Lyn (Dergai et al. 2013), thus participating in viral responses (Arbiser 2015). In addition, SHB associates with the tyrosine phosphatase SHP-2 (PTPN11; protein tyrosine phosphatase, non-receptor 11) via unknown mechanism(s) (Cross et al. 2002). Known SHB-interacting partners are listed in Table 1. SHB-dependent signaling has been shown to influence the activities of downstream signaling intermediates such as extracellular-signalregulated kinase (ERK), PI3K, Rap1, FAK, PLC- $\gamma$ and Rac1, depending on context (Anneren et al. 2003).

SHB has three paralogues: SHD, SHE and SHF (Oda et al. 1997, Lindholm et al. 2000). They all share sequence similarity in the C-terminus and at the phosphorylation sites. In addition, SHD exhibits limited sequence similarity with SHB in the N-terminus. SHD and SHE were identified as c-Abl interacting partners (Oda et al. 1997), whereas SHF was characterized based on sequence homology with SHB (Lindholm et al. 2000). Whereas little is known about the functions of SHD and SHE, SHF has been reported to negatively regulate anaplastic lymphoma kinase (ALK)
Table 1 Summary of SHB domain interactions. Identified interactions between different domains of SHB and various signaling proteins are shown. GHR has been tentatively assigned as a partner interacting with the SHB SH2-domain. LMP2A is an Epstein-Barr virus product

\begin{tabular}{lllll}
$\begin{array}{lll}\text { Proline rich } \\
\text { motifs }\end{array}$ & $\begin{array}{l}\text { PTB } \\
\text { domain }\end{array}$ & $\begin{array}{l}\text { Tyrosine } \\
\text { phosphorylation } \\
\text { sites }\end{array}$ & $\begin{array}{l}\text { SH2 } \\
\text { domain }\end{array}$ \\
\cline { 1 - 1 } $\begin{array}{ll}\text { c-Src } \\
\text { p85 PI3K }\end{array}$ & FAK & CAT & SLP76 & PDGFRA \\
PLC- $\gamma$ & Vav1 & RasGAP & PDGFRB \\
EPS8 & LMP2A & C-Abl & FGFR1 \\
GRB2 & & & TCR \\
JAK1/3 & & & VEGFR2 \\
& & & IL-2R \\
& & & C-Met \\
& & & EphB2 \\
& & & GHR \\
& & & LMP2A
\end{tabular}

signaling (Takagi et al. 2013) and participate in PDGFRA signaling (Lindholm et al. 2000).

\section{SHB in cellular events in non- $\beta$ cells}

Early studies utilized SHB overexpression or expression of a SHB SH2-domain mutant (R522K-SHB) to elucidate SHB's function in cell lines. These revealed pleiotropic effects of SHB such as regulation of apoptosis, differentiation, proliferation and cytoskeletal alterations in various cell types such as fibroblasts, pheochromocytoma PC12 cells, endothelial cells, mouse embryonic stem cells and prostate cancer PC-3 cells (Anneren et al. 2003, Davoodpour et al. 2007, Funa et al. 2008a). The pleiotropicity of these effects is in line with SHB's ability to generate diverse signaling complexes in relation to the cellular context in which SHB is stimulated.

In NIH3T3 fibroblasts, SHB overexpression led to increased apoptosis upon serum deprivation in fibroblasts (Karlsson \& Welsh 1996). Serum-withdrawal (Lu et al. 2002) or the addition of the angiogenesis inhibitors endostatin or angiostatin (Claesson-Welsh et al. 1998, Dixelius et al. 2000) to endothelial cells were associated with increased apoptosis upon SHB overexpression, as was exposure to the anti-tumor agent 2-methoxyestradiol in PC-3 cells (Davoodpour et al. 2007).

Cell adhesion and the cytoskeletal organization were influenced by SHB in fibroblasts (Hooshmand-Rad et al. 2000) and endothelial cells (Funa et al. 2008b). In endothelial cells, this resulted in increased cell spreading (Holmqvist et al. 2003) and tubular morphogenesis

Published by Bioscientifica Ltd 
(Lu et al. 2002). SHB overexpression enhanced cell differentiation of PC12 cells (Karlsson et al. 1998, Lu et al. 2000) and endothelial cells (Lu et al. 2002), whereas absence of SHB or expression of the SH2-domain-inactive mutant R522K-SHB impaired various aspects of mouse embryonic stem cell differentiation (Kriz et al. 2003, Rolny et al. 2005, Kriz et al. 2006, Saldeen et al. 2006, Funa et al. 2008a). SHB expression was required for FGF1-stimulated endothelial cell proliferation (Cross et al. 2002).

\section{The Shb knockout mouse}

The above findings were obtained from studies in various in vitro systems. To assess a role of SHB in vivo, a global Shb-gene knockout mouse was generated. As suspected, this mouse displays various abnormalities in line with SHB's pleiotropic effects in vitro. Most notably, there are reproductive disorders in the $S h b$ knockout mouse (Kriz et al. 2007). The Shb knockout mouse is embryonically lethal on the C57Bl6 mouse background, whereas it is viable on a mixed genetic background and in BALB/c mice. Reduced implantation efficacy, increased numbers of resorptions and more malformations (neural tube closure defects, rotation defects, petechiae, etc.) were all noted in the absence of $S h b$. Thus, fetal malformations are common in Shb mutant embryos (Kriz et al. 2007). In addition, the mutant allele is inherited through a transmission ratio distortion with selective ovulation of oocytes carrying the mutant allele. A more extensive investigation revealed effects of Shb deficiency on oocyte maturation, progression of meiosis, ovulated oocyte integrity and early embryo development (Calounova et al. 2010). Shb knockout oocytes displayed elevated ERK signaling (Calounova et al. 2010).

\section{Hematopoietic abnormalities}

The Shb knockout mouse also displays hematopoietic abnormalities (Gustafsson et al. 2013, 2014a; b). These include reduced peripheral blood lymphocytes and monocytes and a Th2 skewing of the $\mathrm{T}$ cell receptor response upon activation due to elevated basal $\mathrm{T}$ cell receptor signaling in the absence of Shb (Gustafsson et al. 2011). The consequence of these aberrations was an increased propensity for atopic dermatitis upon stimulation with an allergy-inducing agent (Gustafsson et al. 2014b).

The bone marrow of $S h b$ knockout mice displayed a reduced cell number and proliferation of hematopoietic stem cells (HSC) (Gustafsson et al. 2013). When such Shb knockout cells were subject to competitive transplantation experiments, they initially performed well in repopulating bone-marrow-depleted recipients but eventually lagged in efficacy, causing relatively less contribution to the myeloid lineages than wild type (WT) cells at 16 weeks after transplantation. These cells also exhibited elevated basal FAK/Rac1/PAK signaling in the absence of Shb, and the signaling intermediate that appeared mainly responsible for the effects of SHB was FAK, which showed elevated activity in the absence of $S h b$ and which upon its inhibition using a chemical inhibitor increased HSC proliferation. Genotoxic stress-induced HSC proliferation was unaffected by the absence of $S h b$.

When $S h b$ knockout bone marrow was infected with the Philadelphia chromosome $B C R-A B L 1$ oncogene and transplanted to WT recipient mice (Gustafsson et al. $2014 a$ ), the mice developed leukemia more rapidly with shorter latency. Again, this effect was attributed to elevated FAK activity that promoted the proliferation of leukemic cells in the bone marrow. In addition, the Shb knockout leukemic bone marrow promoted the differentiation and proliferation of non-transformed bone marrow cells to mature neutrophils.

\section{Vascular phenotype}

Absence of $S h b$ confers a vascular phenotype as reviewed (Claesson-Welsh \& Welsh 2013). The properties of this includes: reduced tumor and Matrigel angiogenesis (Funa et al. 2009, Akerblom et al. 2012, Christoffersson et al. 2012), reduced vascular permeability (Funa et al. 2009), an altered vascular architecture (Christoffersson et al. 2012), abnormal endothelial and pericyte morphology and ultrastructure (Akerblom et al. 2009, Funa et al. 2009, Akerblom et al. 2012, Christoffersson et al. 2012), reduced blood flow upon ischemia (Christoffersson et al. 2012, Nikpour et al. 2015) and abnormal properties of leukocyte extravasation (Nikpour et al. 2015). Isolated Shb knockout endothelial cells displayed in vitro altered signaling properties with elevated basal FAK, Rac1, Akt, ERK and myosin light chain kinase signaling and reduced ligand (VEGF) responsiveness (Funa et al. 2009, Zang et al. 2013). Cellular morphology was different explaining some of the structural and ultrastructural aberrations of the Shb knockout vasculature (Funa et al. 2009, Zang et al. 2013).

With respect to both tumor angiogenesis and reproduction, $S h b+/-$ mice displayed a phenotype. This indicates that $S h b$ gene expression is under tight control in that a small (50\% or less) change in expression will have an impact on the response.

Published by Bioscientifica Ltd. 


\section{SHB and $\beta$ cells}

Recent mapping of the $\beta$ cell transcriptome indicates that the SHB gene is under significant transcriptional control in $\beta$ cells (Pasquali et al. 2014). Four key $\beta$ cell transcription factors (PDX1, NKX2.2, FOXA2 and NKX6.1) have binding sites in the $S H B$ gene (Pasquali et al. 2014). The first indications of a functional role of SHB in $\beta$ cells were obtained using a transgenic mouse expressing SHB under the control of the rat insulin promoter in $\beta$ cells. In those experiments, SHB overexpression increased the $\beta$ cell mass (Welsh et al. 1999). Increased $\beta$ cell proliferation could not be detected under basal conditions but upon partial pancreatectomy (Anneren 2002). Furthermore, SHB overexpressing $\beta$ cells exhibited increased susceptibility to addition of the cytotoxic cytokines IL1 $\beta$ and IFN- $\gamma$ (Welsh et al. 1999). Thus, a dual response exists to SHB overexpression consisting of increased proliferation but also an increased cytotoxic response to cytokine-induced stress. Whereas the increased proliferation may relate to the increased activation of FAK/IRS/PI3K/ERK (as described below), the augmented stress response could relate to SHB's association with c-Abl (see below). Besides increased proliferation, SHB overexpressing $\beta$ cells have enhanced insulin secretion and the transgenic mouse shows improved glucose tolerance.

SHB overexpression was found to influence the signaling signature of $\beta$ cells. Increased association of FAK with IRS1 and elevated basal IRS1 and IRS2 activities were observed in insulin-producing cells overexpressing SHB (Welsh et al. 2002). These effects translated to basal PI3K and ERK activation with reduced responsiveness to insulin stimulation.

SHB association with c-Abl was found to be required for an appropriate stress response induced by cisplatin (genotoxicity) and tunicamycin (unfolded protein response) in insulin-producing cells (Hagerkvist et al. 2007a). Other studies have implicated the importance of c-Abl for $\beta$ cell survival via knockdown or use of the inhibitor imatinib (Hagerkvist et al. 2005, Hagerkvist et al. 2007b).

In the Shb knockout mouse, elevated basal blood glucose was observed both in mice fed ad libitum and in mice subjected to an over-night starvation period (Akerblom et al. 2009). Pancreas perfusion experiments showed a reduction of the first-phase response to glucose occurring at 1-3 min after glucose stimulation suggesting that the elevated blood glucose values were related to impaired insulin secretion. In further support for this, insulin sensitivity was found to be unaffected by the
Shb genotype (Akerblom et al. 2009). Other $\beta$ cell phenotypes observed in the $S h b$ knockout were decreased microvascular density in islets of Langerhans (Akerblom et al. 2009) and diminished $\beta$ cell death upon exposure to cytotoxic cytokines (IL1 $\beta+$ IFN- $\gamma$ ) (Mokhtari et al. 2009).

Search for an explanation for the reduced first-phase insulin secretion defect by patch-clamp analysis revealed a reduction in the readily releasable pool of granules as a consequence of Shb deficiency, which could be a consequence of a diminished rate of insulin granule supply (Akerblom et al. 2009).

In further attempts to obtain a more complete mechanistic understanding of the impaired first-phase insulin secretory response, the islet-signaling signature was investigated in more detail. In Shb knockout islets, elevated basal FAK, IRS1/2 and Akt activities were observed (Alenkvist et al. 2014). Curiously, this pattern mirrors that observed in SHB-overexpressing $\beta$ cells in which elevated basal FAK, IRS1/2 and Akt activities were also observed in Shb-deficient islets (Welsh et al. 2002). Increased expression and nuclear translocation of $\beta$ catenin was also observed (Alenkvist et al. 2014). Akt affects $\beta$ catenin signaling by phosphorylating and inactivating the GSK3 $\beta$ kinase that in turn regulates the stability of $\beta$ catenin. Consequently, the increased nuclear content of $\beta$ catenin is probably a consequence of elevated Akt activity (Katoh and Katoh 2006). In addition, increased Akt activity is a likely explanation for the reduced $\beta$ cell death upon exposure to cytotoxic cytokines in the absence of Shb (Mokhtari et al. 2009).

Determining mRNA levels of several key proteins involved in the exocytotic process showed no effects of Shb deficiency, suggesting that altered expression of these proteins is an unlikely explanation for the impaired insulin release occurring in the absence of SHB (Alenkvist et al. 2014). There were also no detectable effects on ATP generation, the intracellular $\mathrm{Ca}^{2+}$-concentration or $\mathrm{Ca}^{2+}$. channel activity (Alenkvist et al. 2014). However, the early rise of cAMP in response to glucose was delayed and since cAMP is an important messenger in glucose-induced insulin secretion (Tian et al. 2015), this effect may explain the reduction of first-phase insulin secretion (Akerblom et al. 2009). The delayed cAMP response may be attributed to FAK-regulation of phosphodiesterase activity (Serrels et al. 2010), which upon elevated FAK activity promotes the local breakdown of cAMP in the sub-membrane space (Alenkvist et al. 2014).

Both integrins and glucose promote increased $\beta$ cell FAK activity with enhanced survival, proliferation and insulin secretion as a result (Rondas et al. 2011,

Published by Bioscientifica Ltd 
Cai et al. 2012, Rondas et al. 2012, Arous et al. 2013). The data of the $S h b$ knockout islets suggest negative effects of FAK as well, operating under conditions of chronic over-activity. Altered cAMP signaling is one aspect of this. Another possibility is that elevated basal FAK activity promotes an increased basal insulin secretion in the absence of glucose stimulation, as was observed in Shb knockout pancreas (Akerblom et al. 2009). Such an effect could help explain the observed depletion of the pool of readily releasable granules.

Signaling pathways relevant in $\beta$ cells, hematopoietic cells and endothelial cells that are modulated by the absence of SHB are summarized in Fig. 2. These include PLC- $\gamma$, c-Abl, PI3K, Src-kinase/FAK and Vav1 with consequences for cell survival, proliferation and the cellular cytoskeleton and $\beta$ cell cAMP-signaling regulating insulin secretion.

\section{SHB and the FAK}

The FAK tyrosine kinase is a key element serving a regulatory role at the interface between the extracellular matrix, ligand-stimulated tyrosine kinase/cytokine receptors and intracellular events such as regulation of cell shape, cell motility, the cytoskeleton and signal transduction (Parsons 2003). FAK activity is under complex control involving numerous elements and/or processes (Tomakidi et al. 2014, Lee et al. 2015). The SHB/FAK relationship is described above and this interaction will have implications for several downstream signaling systems, such as the Akt, ERK and Rac1 pathways as observed in $\beta$ cells, endothelial cells and hematopoietic stem cells (Funa et al. 2009, Gustafsson et al. 2013, Alenkvist et al. 2014). Curiously, both SHB overexpression and absence of SHB seem to have similar effects on FAK activity, with increased basal activity and reduced ligand responsiveness. Whereas such effects appear to be plausible consequences of SHB overexpression, it is less apparent why they would also occur in response to SHB deficiency. The response recorded as a consequence of SHB overexpression could result from SHB's ability, via its proline-rich motifs, to interact with Src-family kinases (Karlsson et al. 1995). This complex will then more easily be recruited to focal adhesions via SHB's binding through its PTB domain to partially activated FAK, leading to further stimulation of FAK activity (Holmqvist et al. 2003). Such chronic over-stimulation will desensitize FAK to further ligand activation.

As noted above, increased FAK activity in the absence of SHB is counterintuitive but could result from several mechanisms. One is that maximal FAK responsiveness requires cycles of stimulation/absence of stimulation and

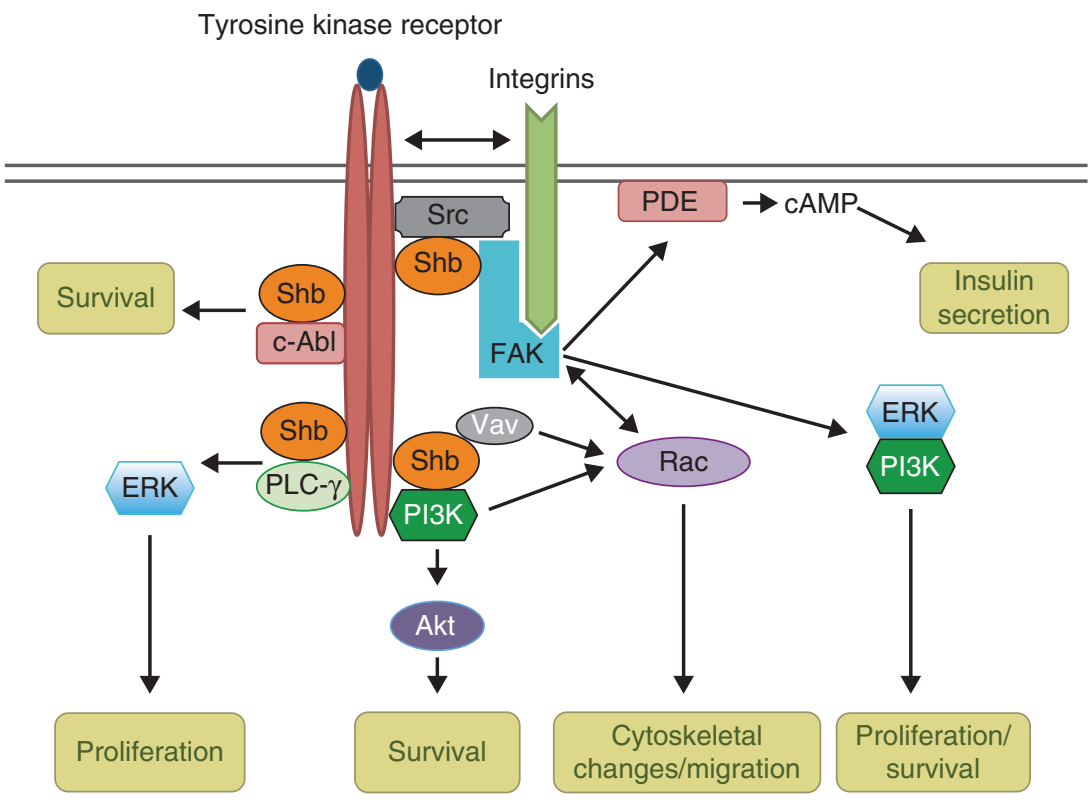

Figure 2

SHB involvement in cellular signaling of particular relevance for $\beta$ cells, hematopoietic cells and endothelial cells. SHB may directly interact with PLC- $\gamma$, c-Abl, PI3K, Src-family kinases, FAK and Vav1. These interactions will Printed in Great Britain
(C) 2016 Society for Endocrinology have pleiotropic effects, including modulating the activities of ERK, Akt, Rac1 and CAMP phosphodiesterase (PDE). Numerous cellular responses will ensue. 
that absence of SHB will disrupt this process. Such an oscillatory pattern of FAK activity does indeed exist, with sequential phosphorylation of tyrosine residues present in FAK during activation culminating with the phosphorylation of Y925. When this occurs, GRB2 binds, paxillin displaces from the complex and the focal adhesion complex disintegrates, allowing another cycle to start (Tomakidi et al. 2014). If SHB plays an important role in the progression of this cycle, desensitization of FAK activity could take place in the absence of SHB since a block may occur at or subsequent to Y397-FAK phosphorylation, thus disrupting progression of the cycle and normal FAK function. An alternative option could be mis-targeting of intracellular Src-family kinases upon SHB depletion. Alternatively, SHB could interact with a phosphatase that dephosphorylates and inactivates FAK, thus promoting FAK activation. The stimulatory effect of SHB deficiency could additionally involve indirect effects via changes in the expression of any of the numerous components that regulate FAK activity, such as cytokines/ growth factors, integrins/extracellular matrix proteins, talin, vinculin, paxillin and FRNK (Tomakidi et al. 2014). Finally, SHB may interact with FAK and regulate FAK activity and availability at locations outside focal adhesions and absence of SHB would then facilitate FAK's recruitment to focal adhesions. The latter possibility lends experimental support from the fact that the SHB protein has not yet been detected as selectively present in focal adhesions (Winograd-Katz et al. 2014).

\section{SHB and inflammation}

A characteristic feature of SHB based on data obtained from the $S h b$ knockout mouse is its involvement in inflammatory processes (Arbiser 2015). An example of this involves effects in $\mathrm{T}$ cells causing an exaggerated Th2-response as described above (Gustafsson et al. 2011, $2014 b$ ). Furthermore, peritoneal recruitment of a specific subset of macrophages was also affected by the absence of Shb (Nikpour et al. 2015). In addition, B16F10 melanoma tumors exhibited less recruitment of $\mathrm{CD} 8+$ cytotoxic $\mathrm{T}$ cells when grown on an Shb-deficient background (Zang et al. 2015). However, studies on the RT2 (RIPTag-2; rat insulin promoter-SV40 large $\mathrm{T}$ antigen) insulinoma model has provided further knowledge on SHB-related inflammatory responses. In that tumor model, VEGFAdependent tumor angiogenesis was reduced by the absence of SHB, causing smaller tumors. However, VEGFA-independent tumor expansion was not affected by $S h b$ deficiency (Akerblom et al. 2012). In order to elucidate the underlying mechanisms, Affymetrix microarray analysis on WT and $S h b$-deficient tumor RNA

Table 2 Summary of Ingenuity analysis of WT and Shb deficient RT2 microarrays. Changes among top pathways, molecular and cellular functions, physiological functions and networks identified by the analysis have been listed

\begin{tabular}{|c|c|}
\hline Top canonical pathways & Top molecular and cellular functions \\
\hline $\begin{array}{l}\text { Leucocyte extravasation } \\
\text { signaling }(+)\end{array}$ & Cellular function and maintenance \\
\hline $\begin{array}{l}\text { Granulocyte adhesion and } \\
\text { diapedesis }(+)\end{array}$ & Cellular development \\
\hline $\begin{array}{l}\text { Fcg receptor-mediated } \\
\text { phagocytosis in macro- } \\
\text { phages and monocytes }(+)\end{array}$ & Cellular growth and proliferation \\
\hline $\begin{array}{l}\text { T-helper-cell differentiation } \\
(+)\end{array}$ & Cellular movement \\
\hline
\end{tabular}

Natural killer cell signaling

Cell-cell signaling and interaction

\section{Top physiological systems \\ Hematological system development and function}

Immune cell trafficking

\section{Tissue development and morphology}

Humoral immune response

Hematopoiesis

\section{Top networks}

Infections disease, humoral immune response, protein synthesis

Inflammatory response, cell-to-cell signaling, cell death and survival

Humoral immune response, protein synthesis, cellular development

Cellular movement, hematological system development and function, immune cell trafficking

Cellular development and growth, hematological system development and function

TCR signaling $(+)$

iCOS-iCOSL signaling in

T helper cells $(+)$

T-cell receptor signaling $(+)$

Crosstalk between dendritic cells and NK cells $(+)$ 
samples was performed. Principal component analysis (PCA) of seven WT and seven Shb + / - tumor microarrays revealed significant heterogeneity in the gene expression patterns between the different tumors, and, in particular, $S h b+/$ - tumors displayed the strongest deviation from the mean. The figure showing the results of the PCA can be found at the website http://www.mcb.uu.se/res/groups/ $\mathrm{mw} / \mathrm{publ} / \mathrm{suppl} /$. The finding suggests variation between different tumors in their adaptation to the limitations of the microenvironment and that, in particular, absence of SHB will promote diversification in developing escape mechanisms from insufficient VEGFA-dependent angiogenesis. Significant changes in microarray gene expression were subjected to Ingenuity analysis and the results have been listed in Table 2 . The top canonical pathways that were significantly altered include those causing myeloid cell extravasation and phagocytosis, $\mathrm{T}$ helper cell differentiation, natural killer cell signaling and inducible T-cell co-stimulator (iCOS) signaling (Table 2). The majority of these responses were increased in the absence of $S h b$. These pathways are predicted to have implications for molecular and cellular functions such as cellular maintenance, development, growth, movement and cell-cell signaling. Consequently, the main physiological systems affected are hematological development and function, immune cell trafficking, tissue development and morphology, humoral immune response and hematopoiesis. These inflammatory alterations are not easily categorized as the belonging to any single well-defined response but rather in concert imply changes in immune/inflammatory reactivity as a key element affected by the absence of SHB. In summary, the data make a strong case for an inflammatory response occurring in Shbdeficient RT2 tumors that substitutes the absence of effective VEGFA-dependent angiogenesis in allowing for tumor expansion. The altered inflammatory profile may include both aberrant properties of the vascular component and the composition of the immune cells that infiltrate the tumors. Tumor-associated macrophages, for instance, have been shown to promote tumor expansion in many studies, thus setting precedent for inflammatory responses rescuing tumor growth when angiogenesis is limiting (Allavena et al. 2008). For access to the complete RT2 microarray data, Ingenuity analysis and PCA, see the website (http://www.mcb.uu.se/res/groups/ $\mathrm{mw} / \mathrm{publ} / \mathrm{suppl} /$ ).

\section{SHB and diabetes}

It is well established that type 2 diabetes (T2D) exhibits a low-grade chronic inflammatory component (McNelis \& Olefsky 2014). This has been shown to promote peripheral insulin resistance in adipose tissue and skeletal muscle. An inflammatory contribution to abnormal $\beta$ cell function may also exist in T2D (Eguchi \& Manabe 2013). The current review suggests that SHB by its regulation of FAK

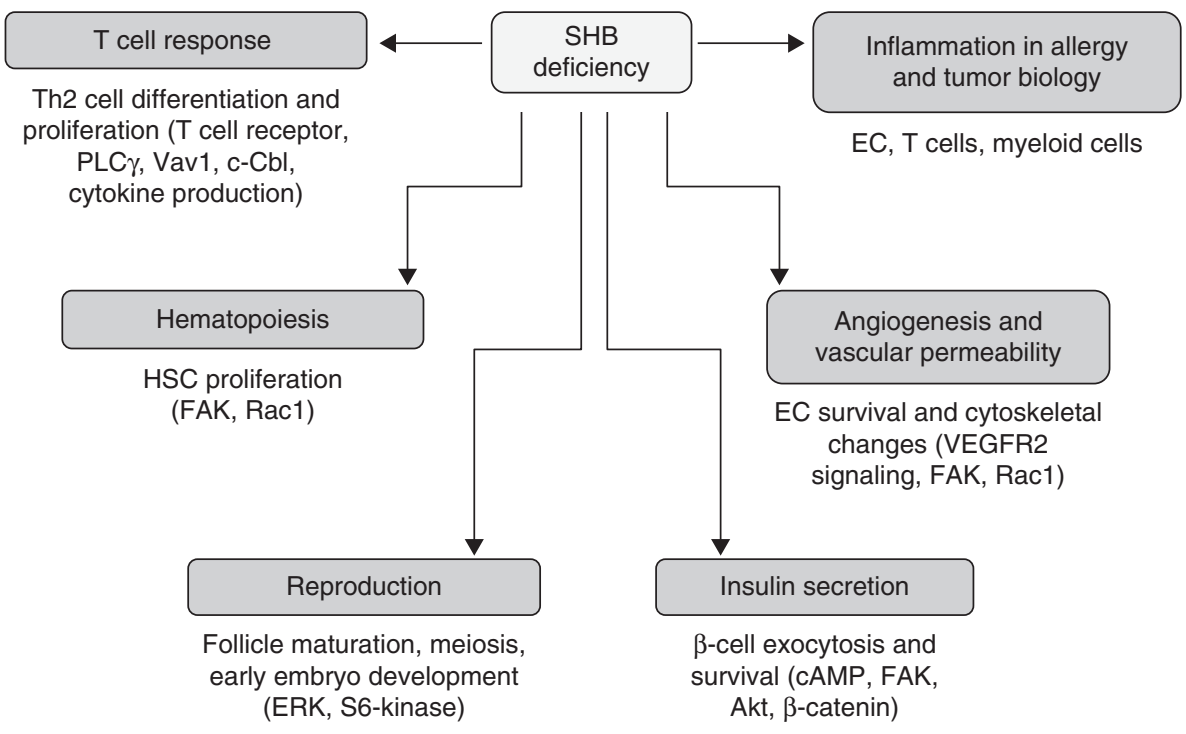

Figure 3

Schematic diagram showing identified physiological responses affected by Shb deficiency. Physiological systems altered are in boxes, below are cell types with aberrant characteristics and, in parenthesis, signaling components involved possibly explaining the effects listed. EC, endothelial cell; HSC, hematopoietic stem cell.

Published by Bioscientifica Ltd. 
activity in numerous cell types, such as $\beta$ cells, endothelial cells and inflammatory hematopoietic cells, will exert an influence on different target organs of relevance to inflammatory homeostasis. Such effects could involve numerous components: an altered signaling signature in $\beta$ cells with chronically elevated FAK and Akt activities, participation in c-Abl-dependent death signaling upon cytotoxic stress, dysfunctional vasculature in islets of Langerhans and skeletal muscle, disturbed myeloid cell extravasation and skewed $\mathrm{T}$ cell responses that cause altered profiles of cytokine production. Although the listed aberrations have been demonstrated in certain systems under specific conditions, it remains unproven whether a systemic low-grade inflammation has any relationship to SHB signaling. This is due to the unfortunate fact that the $S h b$ knockout is not viable on the C57Bl6 background and thus no comprehensive data exist on peripheral inflammation of relevance to the metabolic syndrome in the absence of $S h b$, only indications of alterations in vascular/inflammatory cell function, as mentioned above. Searching human-genome-wide association studies (GWAS) for SHB gene alterations in relation to the type 2 diabetes parameters (Pruim et al. 2010) of fasting glucose levels and HbA1c (http:// locuszoom.sph.umich.edu/locuszoom/) revealed $S H B$ gene single-nucleotide polymorphisms at various positions (rs776023; rs2091415) that correlated with these disease variables at low levels of significance $(0.01<P<0.001)$. Such low levels of significance do not hold up when multiple comparisons are done, as is the case for GWAS. If indicative of anything, the associations could suggest that $S H B$ gene alterations play a role in glucose homeostasis in subpopulations of the disease, or, alternatively, that other genetic markers for the $S H B$ gene that hitherto have not been investigated show closer associations with the metabolic variables. More in-depth analysis is required to elucidate these possibilities. An additionally relevant aspect to explore would be the relationship between type 1 diabetes and the $S H B$ gene, since the pathogenic mechanisms of that disease involve all or most of the aspects that SHB has been shown to regulate.

\section{Summary and conclusions}

SHB is a ubiquitously expressed adapter protein, which participates in diverse signaling pathways, thus affecting signaling efficiency and downstream events. Its expression is under tight control, since a small change in expression has been shown to result in an altered signaling outcome.
Research on SHB has so far focused on its role in $\beta$ cells/diabetes, reproduction, hematopoiesis, angiogenesis and inflammatory processes as schematically outlined in Fig. 3. Consequently, SHB is implicated as a multifaceted cellular signaling component active in different scenarios, probably by coordinating physiological responses in relevant cell populations.

\section{Declaration of interest}

The authors declare that there is no conflict of interest that could be perceived as prejudicing the impartiality of this review.

\section{Funding}

The work was supported by the Swedish Diabetes Foundation, the Swedish Cancer Foundation and the Family Ernfors Fund. The microarrays were performed by the Uppsala Array Platform, Department of Medical Science, Science for Life Laboratory, Uppsala University, Uppsala.

\section{Acknowledgements}

We are grateful to Nils Welsh and Anders Tengholm at the Department of Medical Cell Biology, Uppsala University, for comments.

\section{References}

Akerblom B, Barg S, Calounova G, Mokhtari D, Jansson L \& Welsh M 2009 Impaired glucose homeostasis in Shb-/ - mice. Journal of Endocrinology 203 271-279. (doi:10.1677/JOE-09-0198)

Akerblom B, Zang G, Zhuang ZW, Calounova G, Simons M \& Welsh M 2012 Heterogeneity among RIP-Tag2 insulinomas allows vascular endothelial growth factor-A independent tumor expansion as revealed by studies in Shb mutant mice: implications for tumor angiogenesis. Molecular Oncology 6 333-346. (doi:10.1016/j.molonc.2012.01.006)

Alenkvist I, Dyachok O, Tian G, Li J, Mehrabanfar S, Jin Y, Birnir B, Tengholm A \& Welsh M 2014 Absence of Shb impairs insulin secretion by elevated FAK activity in pancreatic islets. Journal of Endocrinology $\mathbf{2 2 3}$ 267-275. (doi:10.1530/JOE-14-0531)

Allavena P, Sica A, Garlanda C \& Mantovani A 2008 The Yin-Yang of tumorassociated macrophages in neoplastic progression and immune surveillance. Immunological Reviews 222 155-161. (doi:10.1111/ j.1600-065X.2008.00607.x)

Anneren C 2002 Dual role of the tyrosine kinase GTK and the adaptor protein SHB in $\beta$-cell growth: enhanced $\beta$-cell replication after $60 \%$ pancreatectomy and increased sensitivity to streptozotocin. Journal of Endocrinology 172 145-153. (doi:10.1677/joe.0.1720145)

Anneren C, Lindholm CK, Kriz V \& Welsh M 2003 The FRK/RAK-SHB signaling cascade: a versatile signal-transduction pathway that regulates cell survival, differentiation and proliferation. Current Molecular Medicine 3 313-324. (doi:10.2174/1566524033479744)

Arbiser JL 2015 A tale of two macrophages: to Shb or not to Shb. Acta Physiologica 214 152-153. (doi:10.1111/apha.12504)

Arous C, Rondas D \& Halban PA 2013 Non-muscle myosin IIA is involved in focal adhesion and actin remodelling controlling glucose-stimulated insulin secretion. Diabetologia 56 792-802. (doi:10.1007/s00125-0122800-1)

Cai EP, Casimir M, Schroer SA, Luk CT, Shi SY, Choi D, Dai XQ, Hajmrle C, Spigelman AF, hu D et al. 2012 In vivo role of focal adhesion kinase in regulating pancreatic $\beta$-cell mass and function through insulin 
signaling, actin dynamics, and granule trafficking. Diabetes $\mathbf{6 1}$ 1708-1718. (doi:10.2337/db11-1344)

Calounova G, Livera G, Zhang XQ, Liu K, Gosden RG \& Welsh M 2010 The Src homology 2 domain-containing adapter protein B (SHB) regulates mouse oocyte maturation. PLOS ONE 5 e11155. (doi:10.1371/ journal.pone.0011155)

Christoffersson G, Zang G, Zhuang ZW, Vagesjo E, Simons M, Phillipson M \& Welsh M 2012 Vascular adaptation to a dysfunctional endothelium as a consequence of Shb deficiency. Angiogenesis 15 469-480. (doi:10.1007/s10456-012-9275-z)

Claesson-Welsh L \& Welsh M 2013 VEGFA and tumour angiogenesis. Journal of Internal Medicine 273 114-127. (doi:10.1111/joim.12019)

Claesson-Welsh L, Welsh M, Ito N, Anand-Apte B, Soker S, Zetter B, O'Reilly M \& Folkman J 1998 Angiostatin induces endothelial cell apoptosis and activation of focal adhesion kinase independently of the integrin-binding motif RGD. PNAS 95 5579-5583. (doi:10.1073/pnas. 95.10.5579)

Cross MJ, Lu L, Magnusson P, Nyqvist D, Holmqvist K, Welsh M \& Claesson-Welsh L 2002 The Shb adaptor protein binds to tyrosine 766 in the FGFR-1 and regulates the Ras/MEK/MAPK pathway via FRS2 phosphorylation in endothelial cells. Molecular Biology of the Cell $\mathbf{1 3}$ 2881-2893. (doi:10.1091/mbc.E02-02-0103)

Davoodpour P, Landstrom M \& Welsh M 2007 Reduced tumor growth in vivo and increased c-Abl activity in PC3 prostate cancer cells overexpressing the Shb adapter protein. BMC Cancer 7161. (doi:10.1186/1471-2407-7-161)

Dergai O, Dergai M, Skrypkina I, Matskova L, Tsyba L, Gudkova D \& Rynditch A 2013 The LMP2A protein of Epstein-Barr virus regulates phosphorylation of ITSN1 and Shb adaptors by tyrosine kinases. Cellular Signalling 25 33-40. (doi:10.1016/j.cellsig.2012.09.011)

Dixelius J, Larsson H, Sasaki T, Holmqvist K, Lu L, Engstrom A, Timpl R, Welsh M \& Claesson-Welsh L 2000 Endostatin-induced tyrosine kinase signaling through the Shb adaptor protein regulates endothelial cell apoptosis. Blood 95 3403-3411.

Eguchi K \& Manabe I 2013 Macrophages and islet inflammation in type 2 diabetes. Diabetes, Obesity \& Metabolism 15 (Suppl 3) 152-158. (doi:10.1111/dom.12168)

Funa NS, Saldeen J, Akerblom B \& Welsh M 2008a Interdependent fibroblast growth factor and activin A signaling promotes the expression of endodermal genes in differentiating mouse embryonic stem cells expressing Src Homology 2-domain inactive Shb. Differentiation 76 443-453. (doi:10.1111/j.1432-0436. 2007.00249.x)

Funa NS, Reddy K, Bhandarkar S, Kurenova EV, Yang L, Cance WG, Welsh M \& Arbiser JL $2008 b$ Shb gene knockdown increases the susceptibility of SVR endothelial tumor cells to apoptotic stimuli in vitro and in vivo. Journal of Investigative Dermatology 128 710-716. (doi:10.1038/sj.jid.5701057)

Funa NS, Kriz V, Zang G, Calounova G, Akerblom B, Mares J, Larsson E, Sun Y, Betsholtz C \& Welsh M 2009 Dysfunctional microvasculature as a consequence of shb gene inactivation causes impaired tumor growth. Cancer Research 69 2141-2148. (doi:10.1158/0008-5472.CAN-08-3797)

Gustafsson K, Calounova G, Hjelm F, Kriz V, Heyman B, Gronvik KO, Mostoslavsky G \& Welsh M 2011 Shb deficient mice display an augmented TH2 response in peripheral CD4+ T cells. BMC Immunology 12 3. (doi:10.1186/1471-2172-12-3)

Gustafsson K, Heffner G, Wenzel PL, Curran M, Grawe J, McKinneyFreeman SL, Daley GQ \& Welsh M 2013 The Src homology 2 protein Shb promotes cell cycle progression in murine hematopoietic stem cells by regulation of focal adhesion kinase activity. Experimental Cell Research 319 1852-1864. (doi:10.1016/j.yexcr.2013.03.020)

Gustafsson K, Jamalpour M, Trinh C, Kharas MG \& Welsh M 2014a The Src homology-2 protein Shb modulates focal adhesion kinase signaling in a BCR-ABL myeloproliferative disorder causing accelerated progression of disease. Journal of Hematology \& Oncology 7 45. (doi:10.1186/ $1756-8722-7-45)$
Gustafsson K, Willebrand E \& Welsh M $2014 b$ Absence of the adaptor protein Shb potentiates the T helper type 2 response in a mouse model of atopic dermatitis. Immunology 143 33-41. (doi:10.1111/imm.12286)

Hagerkvist R, Mokhtari D, Myers JW, Tengholm A \& Welsh N 2005 siRNA produced by recombinant dicer mediates efficient gene silencing in islet cells. Annals of the New York Academy of Sciences 1040 114-122. (doi:10.1196/annals.1327.014)

Hagerkvist R, Mokhtari D, Lindholm C, Farnebo F, Mostoslavsky G, Mulligan RC, Welsh N \& Welsh M 2007a Consequences of Shb and c-Abl interactions for cell death in response to various stress stimuli. Experimental Cell Research 313 284-291. (doi:10.1016/j.yexcr. 2006.10.011)

Hagerkvist R, Sandler S, Mokhtari D \& Welsh N 2007b Amelioration of diabetes by imatinib mesylate (Gleevec): role of $\beta$-cell NF- $\kappa \mathrm{B}$ activation and anti-apoptotic preconditioning. FASEB Journal 21 618-628. (doi:10.1096/fj.06-6910com)

Holmqvist K, Cross M, Riley D \& Welsh M 2003 The Shb adaptor protein causes Src-dependent cell spreading and activation of focal adhesion kinase in murine brain endothelial cells. Cellular Signalling 15 171-179. (doi:10.1016/S0898-6568(02)00076-1)

Holmqvist K, Cross MJ, Rolny C, Hagerkvist R, Rahimi N, Matsumoto T, Claesson-Welsh L \& Welsh M 2004 The adaptor protein shb binds to tyrosine 1175 in vascular endothelial growth factor (VEGF) receptor-2 and regulates VEGF-dependent cellular migration. Journal of Biological Chemistry 279 22267-22275. (doi:10.1074/jbc.M312729200)

Hooshmand-Rad R, Lu L, Heldin CH, Claesson-Welsh L \& Welsh M 2000 Platelet-derived growth factor-mediated signaling through the Shb adaptor protein: effects on cytoskeletal organization. Experimental Cell Research 257 245-254. (doi:10.1006/excr.2000.4896)

Jorgensen C, Sherman A, Chen GI, Pasculescu A, Poliakov A, Hsiung M, Larsen B, Wilkinson DG, Linding R \& Pawson T 2009 Cell-specific information processing in segregating populations of Eph receptor ephrin-expressing cells. Science 326 1502-1509. (doi:10.1126/ science.1176615)

Karlsson T \& Welsh M 1996 Apoptosis of NIH3T3 cells overexpressing the Src homology 2 domain protein Shb. Oncogene 13 955-961.

Karlsson T, Songyang Z, Landgren E, Lavergne C, Di Fiore PP, Anafi M, Pawson T, Cantley LC, Claesson-Welsh L \& Welsh M 1995 Molecular interactions of the Src homology 2 domain protein Shb with phosphotyrosine residues, tyrosine kinase receptors and Src homology 3 domain proteins. Oncogene 10 1475-1483.

Karlsson T, Kullander K \& Welsh M 1998 The Src homology 2 domain protein Shb transmits basic fibroblast growth factor- and nerve growth factor-dependent differentiation signals in PC12 cells. Cell Growth \& Differentiation 9 757-766.

Katoh M \& Katoh M 2006 Cross-talk of WNT and FGF signaling pathways at GSK3 $\beta$ to regulate $\beta$-catenin and SNAIL signaling cascades. Cancer Biology \& Therapy 5 1059-1064. (doi:10.4161/cbt.5.9.3151)

Kriz V, Anneren C, Lai C, Karlsson J, Mares J \& Welsh M 2003 The SHB adapter protein is required for efficient multilineage differentiation of mouse embryonic stem cells. Experimental Cell Research 286 40-56. (doi:10.1016/S0014-4827(03)00099-5)

Kriz V, Agren N, Lindholm CK, Lenell S, Saldeen J, Mares J \& Welsh M 2006 The SHB adapter protein is required for normal maturation of mesoderm during in vitro differentiation of embryonic stem cells. Journal of Biological Chemistry 281 34484-34491. (doi:10.1074/jbc. M604084200)

Kriz V, Mares J, Wentzel P, Funa NS, Calounova G, Zhang XQ, ForsbergNilsson K, Forsberg M \& Welsh M 2007 Shb null allele is inherited with a transmission ratio distortion and causes reduced viability in utero. Developmental Dynamics 236 2485-2492. (doi:10.1002/dvdy.21257)

Lee BY, Timpson P, Horvath LG \& Daly RJ 2015 FAK signaling in human cancer as a target for therapeutics. Pharmacology \& Therapeutics 146C 132-149. (doi:10.1016/j.pharmthera.2014.10.001)

Leung KK, Hause RJ Jr, Barkinge JL, Ciaccio MF, Chuu CP \& Jones RB 2014 Enhanced prediction of Src homology 2 (SH2) domain binding 
potentials using a fluorescence polarization-derived c-Met, c-Kit, ErbB, and androgen receptor interactome. Molecular \& Cellular Proteomics 13 1705-1723. (doi:10.1074/mcp.M113.034876)

Lindholm CK 2002 IL-2 receptor signaling through the Shb adapter protein in T and NK cells. Biochemical and Biophysical Research Communications 296 929-936. (doi:10.1016/S0006-291X(02)02016-8)

Lindholm CK, Frantz JD, Shoelson SE \& Welsh M 2000 Shf, a Shb-like adapter protein, is involved in PDGF- $\alpha$-receptor regulation of apoptosis. Biochemical and Biophysical Research Communications 278 537-543. (doi:10.1006/bbrc.2000.3847)

Liu BA, Engelmann BW, Jablonowski K, Higginbotham K, Stergachis AB \& Nash PD 2012 SRC homology 2 domain binding sites in insulin, IGF-1 and FGF receptor mediated signaling networks reveal an extensive potential interactome. Cell Communication and Signaling 1027. (doi:10.1186/1478-811X-10-27)

Lu L, Anneren C, Reedquist KA, Bos JL \& Welsh M 2000 NGF-dependent neurite outgrowth in PC12 cells overexpressing the Src homology 2 -domain protein shb requires activation of the Rap1 pathway. Experimental Cell Research 259 370-377. (doi:10.1006/excr.2000.4984)

Lu L, Holmqvist K, Cross M \& Welsh M 2002 Role of the Src homology 2 domain-containing protein $\mathrm{Shb}$ in murine brain endothelial cell proliferation and differentiation. Cell Growth \& Differentiation 13 141-148.

Matskova LV, Helmstetter C, Ingham RJ, Gish G, Lindholm CK, Ernberg I, Pawson T \& Winberg G 2007 The Shb signalling scaffold binds to and regulates constitutive signals from the Epstein-Barr virus LMP2A membrane protein. Oncogene 26 4908-4917. (doi:10.1038/sj.onc. 1210298)

McNelis JC \& Olefsky JM 2014 Macrophages, immunity, and metabolic disease. Immunity 41 36-48. (doi:10.1016/j.immuni.2014.05.010)

Mokhtari D, Kerblom B, Mehmeti I, Wang X, Funa NS, Olerud J, Lenzen S, Welsh N \& Welsh M 2009 Increased Hsp70 expression attenuates cytokine-induced cell death in islets of Langerhans from Shb knockout mice. Biochemical and Biophysical Research Communications $\mathbf{3 8 7}$ 553-557. (doi:10.1016/j.bbrc.2009.07.051)

Moutoussamy S, Renaudie F, Lago F, Kelly PA \& Finidori J 1998 Grb10 identified as a potential regulator of growth hormone $(\mathrm{GH})$ signaling by cloning of GH receptor target proteins. Journal of Biological Chemistry 273 15906-15912. (doi:10.1074/jbc.273.26.15906)

Nikpour M, Gustafsson K, Vagesjo E, Seignez C, Giraud A, Phillipson M \& Welsh M 2015 Shb deficiency in endothelium but not in leucocytes is responsible for impaired vascular performance during hindlimb ischaemia. Acta Physiologica 214 200-209. (doi:10.1111/apha.12448)

Oda T, Kujovich J, Reis M, Newman B \& Druker BJ 1997 Identification and characterization of two novel SH2 domain-containing proteins from a yeast two hybrid screen with the ABL tyrosine kinase. Oncogene 15 1255-1262. (doi:10.1038/sj.onc.1201299)

Parsons JT 2003 Focal adhesion kinase: the first ten years. Journal of Cell Science 116 1409-1416. (doi:10.1242/jcs.00373)

Pasquali L, Gaulton KJ, Rodriguez-Segui SA, Mularoni L, Miguel-Escalada I, Akerman I, Tena JJ, Moran I, Gomez-Marin C, van de Bunt M et al. 2014 Pancreatic islet enhancer clusters enriched in type 2 diabetes riskassociated variants. Nature Genetics 46 136-143. (doi:10.1038/ng.2870)

Pruim RJ, Welch RP, Sanna S, Teslovich TM, Chines PS, Gliedt TP, Boehnke M, Abecasis GR \& Willer CJ 2010 LocusZoom: regional visualization of genome-wide association scan results. Bioinformatics $\mathbf{2 6}$ 2336-2337. (doi:10.1093/bioinformatics/btq419)

Rolny C, Lu L, Agren N, Nilsson I, Roe C, Webb GC \& Welsh M 2005 Shb promotes blood vessel formation in embryoid bodies by augmenting vascular endothelial growth factor receptor- 2 and platelet-derived growth factor receptor- $\beta$ signaling. Experimental Cell Research $\mathbf{3 0 8}$ 381-393. (doi:10.1016/j.yexcr.2005.04.020)
Rondas D, Tomas A \& Halban PA 2011 Focal adhesion remodeling is crucial for glucose-stimulated insulin secretion and involves activation of focal adhesion kinase and paxillin. Diabetes 60 1146-1157. (doi:10.2337/ db10-0946)

Rondas D, Tomas A, Soto-Ribeiro M, Wehrle-Haller B \& Halban PA 2012 Novel mechanistic link between focal adhesion remodeling and glucose-stimulated insulin secretion. Journal of Biological Chemistry $\mathbf{2 8 7}$ 2423-2436. (doi:10.1074/jbc.M111.279885)

Saldeen J, Kriz V, Agren N \& Welsh M 2006 SHB and angiogenic factors promote ES cell differentiation to insulin-producing cells. Biochemical and Biophysical Research Communications 344 517-524. (doi:10.1016/j. bbrc.2006.03.129)

Serrels B, Sandilands E, Serrels A, Baillie G, Houslay MD, Brunton VG, Canel M, Machesky LM, Anderson KI \& Frame MC 2010 A complex between FAK, RACK1, and PDE4D5 controls spreading initiation and cancer cell polarity. Current Biology 20 1086-1092. (doi:10.1016/ j.cub.2010.04.042)

Takagi D, Tatsumi Y, Yokochi T, Takatori A, Ohira M, Kamijo T, Kondo S, Fujii Y \& Nakagawara A 2013 Novel adaptor protein Shf interacts with ALK receptor and negatively regulates its downstream signals in neuroblastoma. Cancer Science 104 563-572. (doi:10.1111/cas.12115)

Terazono K, Uchiyama Y, Ide M, Watanabe T, Yonekura H, Yamamoto H \& Okamoto H 1990 Expression of reg protein in rat regenerating islets and its co-localization with insulin in the $\beta$ cell secretory granules. Diabetologia 33 250-252. (doi:10.1007/BF00404804)

Tian G, Sol ER, Xu Y, Shuai H \& Tengholm A 2015 Impaired cAMP generation contributes to defective glucose-stimulated insulin secretion after long-term exposure to palmitate. Diabetes 64 904-915. (doi:10.2337/db14-1036)

Tomakidi P, Schulz S, Proksch S, Weber W \& Steinberg T 2014 Focal adhesion kinase (FAK) perspectives in mechanobiology: implications for cell behaviour. Cell and Tissue Research 357 515-526. (doi:10.1007/ s00441-014-1945-2)

Welsh M, Christmansson L, Karlsson T, Sandler S \& Welsh N 1999 Transgenic mice expressing Shb adaptor protein under the control of rat insulin promoter exhibit altered viability of pancreatic islet cells. Molecular Medicine 5 169-180. (doi:10.1007/s008940050116)

Welsh M, Mares J, Karlsson T, Lavergne C, Breant B \& Claesson-Welsh L $1994 \mathrm{Shb}$ is a ubiquitously expressed Src homology 2 protein. Oncogene 9 19-27.

Welsh M, Songyang Z, Frantz JD, Trub T, Reedquist KA, Karlsson T, Miyazaki M, Cantley LC, Band H \& Shoelson SE 1998 Stimulation through the $\mathrm{T}$ cell receptor leads to interactions between SHB and several signaling proteins. Oncogene 16 891-901. (doi:10.1038/sj.onc. 1201607)

Welsh N, Makeeva N \& Welsh M 2002 Overexpression of the Shb SH2 domain-protein in insulin-producing cells leads to altered signaling through the IRS-1 and IRS-2 proteins. Molecular Medicine 8 695-704.

Winograd-Katz SE, Fassler R, Geiger B \& Legate KR 2014 The integrin adhesome: from genes and proteins to human disease. Nature Reviews. Molecular Cell Biology 15 273-288. (doi:10.1038/nrm3769)

Zang G, Christoffersson G, Tian G, Harun-Or-Rashid M, Vagesjo E, Phillipson M, Barg S, Tengholm A \& Welsh M 2013 Aberrant association between vascular endothelial growth factor receptor-2 and VE-cadherin in response to vascular endothelial growth factor-a in Shb-deficient lung endothelial cells. Cellular Signalling 25 85-92. (doi:10.1016/j. cellsig.2012.09.018)

Zang G, Gustafsson K, Jamalpour M, Hong J, Genove G \& Welsh M 2015 Vascular dysfunction and increased metastasis of B16F10 melanomas in Shb deficient mice as compared with their wildtype counterparts. BMC Cancer 15 234. (doi:10.1186/s12885-015-1269-y)

Received in final form 15 October 2015

Accepted 20 October 2015

Accepted Preprint published online 20 October 2015 http://jme.endocrinology-journals.org

DOI: 10.1530/JME-15-0228
() 2016 Society for Endocrinology Printed in Great Britain
Published by Bioscientifica Ltd 